LA-UR- 0905523

Approved for public release;

distribution is unlimited.

Title:

DYNAMIC-TENSILE-EXTRUSION RESPONSE OF FLUOROPOLYMERS

Author(s):

Eric N. Brown, Carl P. Trujillo, George T. Gray III

Intended for:

APS SCCM

Los Alamos National Laboratory, an affirmative action/equal opportunity employer, is operated by the Los Alamos National Security, LLC for the National Nuclear Security Administration of the U.S. Department of Energy under contract DE-AC52-06NA25396. By acceptance of this article, the publisher recognizes that the U.S. Government retains a nonexclusive, royalty-free license to publish or reproduce the published form of this contribution, or to allow others to do so, for U.S. Government purposes. Los Alamos National Laboratory requests that the publisher identify this article as work performed under the auspices of the U.S. Department of Energy. Los Alamos National Laboratory strongly supports academic freedom and a researcher's right to publish; as an institution, however, the Laboratory does not endorse the viewpoint of a publication or guarantee its technical correctness

Form $836(7 / 06)$ 


\title{
DYNAMIC-TENSILE-EXTRUSION RESPONSE OF FLUOROPOLYMERS
}

\author{
E.N. Brown', C.P. Trujillo ${ }^{2}$, G.T. Gray III ${ }^{2}$ \\ 'Los Alamos National Laboratory, ADWP, Los Alamos, NM 87545 USA \\ ${ }^{2}$ Los Alamos National Laboratory, MST-8, Los Alamos, NM 87545 USA
}

\begin{abstract}
The current work applies the recently developed Dynamic-Tensile-Extrusion (Dyn-Ten-Ext) technique to polytetrafluoroethylene (PTFE) and polychlorotrifluoroethylene (PCTFE). Similar to the Taylor Impact Rod, Dynamic-Tensile-Extrusion is a strongly integrated test, probing a wide range of strain rates and stress states. However, the stress state is primarily tensile enabling investigation of dynamic tensile failure modes. Here we investigate the influence of this propensity to neck or not between PCTFE and PTFE on their response under dynamic tensile extrusion loading. The results of the Dyn-Ten-Ext technique are compared with two classic techniques. Both polymers have been investigated using Tensile Split Hopkinson Pressure Bar. The quasistatic and dynamic responses of both fluoropolymers have been extensively characterized. The two polymers exhibit significantly different failure behavior under tensile loading at moderate strain rates. Polytetrafluoroethylene resists formation of a neck and exhibits significant strain hardening. Independent of temperature or strain rate, PTFE sustains true strains to failure of approximately 1.5. Polychlorotrifluoroethylene, on the other hand, consistently necks at true strains of approximately 0.05 .
\end{abstract}

Keywords: Dynamic-Tensile-Extrusion (Dyn-Ten-Ext), Polytetrafluoroethylene (PTFE), Polychlorotrifluoroethylene (PCTFE)

PACS: $62.40 .+\mathrm{i}, 62.50 .+\mathrm{p}$

\section{INTRODUCTION}

The quasi-static and dynamic responses of polytetrafluoroethylene (PTFE, Teflon) $[1-15]$ and polychlorotrifluoroethylene (PCTFE, Kel-F 81) $[1,16]$ have been extensively characterized. Both polymers are semicrystalline, with PCTFE having one out of every four fluorine atoms along the polymer backbone substitutive with a chlorine atom. Structurally, this substitution does not significantly change the level of crystallinity or the density, but does suppress the crystalline phase transitions observed in PTFE [2-6]. The properties are more notably modified by this addition, with the longitudinal and transverse sound speeds increased by approximately $50 \%$ and the flow stress of PCTFE

\footnotetext{
' Corresponding author: en_brown@lanl.gov
}

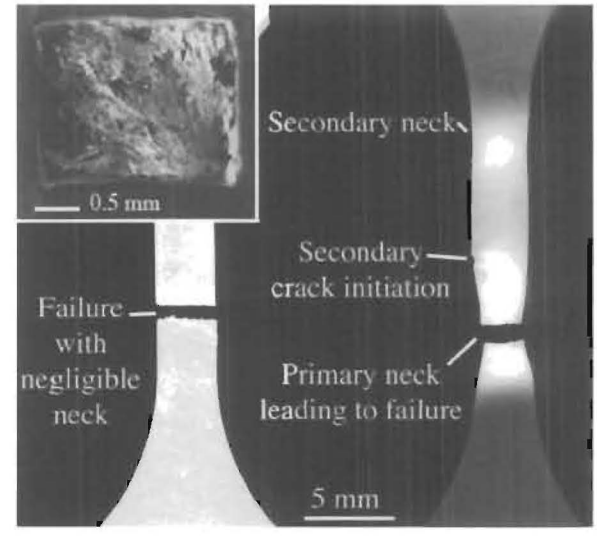

Figure 1. Tensile failure modes with or without necking ((right) room temperature necking of PCTFE [16], (inset) of PTFE fracture surface without necking [6]). 
TABLE 1. Material properties for polymers in the current work [1]

\begin{tabular}{cccccccc}
\hline Material & Density $\left(\mathrm{kg} / \mathrm{m}^{3}\right)$ & Crystallinity $(\%)$ & $\mathrm{C}_{1}(\mathrm{~m} / \mathrm{s})$ & $\mathrm{C}_{\mathrm{s}}(\mathrm{m} / \mathrm{s})$ & $\mathrm{T}_{\mathrm{g}}\left({ }^{\circ} \mathrm{C}\right)$ & $\mathrm{T}_{\mathrm{m}}\left({ }^{\circ} \mathrm{C}\right)$ & Phase Transition $\left({ }^{\circ} \mathrm{C}\right)$ \\
\hline PTFE & 2169 & 38 & 1333 & 506 & $-100,127$ & 328 & 19,30 \\
PCTFE & 2158 & 46 & 1870 & 780 & 48 & 215 & - \\
\hline
\end{tabular}

being two to four times greater than that of PTFE for a given condition of temperatures ranging from -100 to $150^{\circ} \mathrm{C}$ and strain rates from $10^{-4}$ to $3200 \mathrm{~s}^{-1}$ $[1,6,7,16]$. The two polymers also exhibit significantly different failure behavior under tensile loading. Polytetrafluoroethylene resists formation of a neck and exhibits significant strain hardening (Fig. 1) [6]. Independent of temperature or strain rate, PTFE sustains true strains to failure of approximately 1.5. On the other hand, PCTFE consistently necks at true strains of $\sim 0.05$ [16]. Below the glass transition temperature $\left(48^{\circ} \mathrm{C}\right)$ in PCTFE necking is unstable (Fig. 1), resulting in either a decreasing ability to bare load or dynamic failure. Above the glass transition temperature, the neck is stable but the total elongation remains significantly less than observed for PTFE.

In this study we investigate the response of PCTFE and PTFE under Dynamic-Tensile-Extrusion (Dyn-Ten-Ext). The Dyn-Ten-Ext technique was original developed for metals and applied to copper and tantalum spheres by Gray et al., $[17,18]$ as a tensile corollary to compressive Taylor Cylinder Impact testing [19]. Similar to Taylor testing, DynTen-Ext is a strongly integrated test, probing a wide range of strain rates, plastic strains, and stress states. A light gas gun is employed to drive $7.62 \mathrm{~mm}$ diameter samples at velocities on the order of hundreds of meters per second. However, unlike the case of the Taylor Impact test where a rod is driven into a semi-infinite steel block, the Dyn-Ten-Ext test drives the sample through an extrusion die. The resulting stress state is more dominantly tensile leading to dynamic tensile elongation followed by necking, particulation, and finally failure.

\section{EXPERIMENTAL TECHNIQUES}

This investigation was performed on semicrystalline PTFE and PCTFE commercial plate materials. The pedigree of these materials has been characterized and key properties are presented in Table 1. Spherical specimens, $7.58 \mathrm{~mm}$ in diameter, where machined from the two polymers. Dynamic tensile extrusion tests were conducted in a modified
$7.62 \mathrm{~mm}$ diameter Taylor cylinder facility $[17,18]$. Polymer spheres were accelerated in a He-gas launcher at a range of speeds up to $1000 \mathrm{~m} \mathrm{~s}^{-1}$ into a high-strength steel extrusion die (A2 or S7 tool steel with Rockwell hardness 56 and 54 , respectively) designed with an entrance diameter of $7.62 \mathrm{~mm}$ and an exit diameter of $2.8 \mathrm{~mm}$ (a reduction of $63 \%$ ). The post-extrusion macroscopic evolution of the samples upon exiting the extrusion die was captured using high-speed photography and segments coming out of the die were soft captured by a technique described in Refs. [17,20]. An Imacon 200 highspeed camera was used to photograph the experiments. This camera is capable of taking up to 16 frames at a maximum rate corresponding to $200 \times 106$ frames/s. The exposure time and inter-frame time (IFT) of each exposure are fully programmable, and set to $500 \mathrm{~ns}$ and $15 \mu \mathrm{s}$ respectively.

\section{RESULTS AND DISCUSSION}

As shown in Fig. 2, both polymers investigated by the Dyn-Ten-Ext technique in the current work exhibited a threshold under which extrusion through the die was not observed: 164 and $259 \mathrm{~m} \mathrm{~s}^{-1}$ for PTFE and PCTFE, respectively. This threshold is analogous to the ductile-to-brittle transition previously reported for Taylor Impact loading of these two polymers. Both PTFE and PCTFE have been investigated using Tensile Split Hopkinson Pressure Bar testing $[1,7,8,16]$. While PTFE exhibits tensile flow stress values and strain hardening rates at these high strain rates that extrapolate from lower strain rate measurements, the PCTFE necks and fails before the sample has an opportunity to "ring up" and achieve uniaxial stress state stability. Under Taylor Impact Rod loading both PTFE $[3,4]$ and PCTFE [16] exhibit a classic three-diameter ductile deformation pattern, i.e. corresponding to the undeformed diameter away from the impact face, an intermediate region that relatively uniform plastic deformation, and a highly deformed region adjoining the impact face. The ductile-to-brittle transition in PTFE occurs at $131 \mathrm{~m} \mathrm{~s}^{-1}$ with a very tight transition range of less than $4 \mathrm{~m} \mathrm{~s}^{-1}$. This has 
been shown to be a direct result of driving the crystalline domains through a pressure-induced phase transition [3]. Conversely, the ductile-tobrittle transition in PCTFE occurs between 165 and $200 \mathrm{~m} \mathrm{~s}^{-i}$ with a gradual transition to stochastic crack formation and ultimately failure. At the lower end of the ductile-to-brittle transition the velocity for the onset of damage in PCTFE was 26\% higher than PTFE, while at the upper end the velocity was $48 \%$ higher. The much wider transition range in PCTFE was associated with a gradual in-growth of damage. While stochastic, at the lower end of the velocity range, damage took the form of one or two small penny-shaped cracks associated in the location with

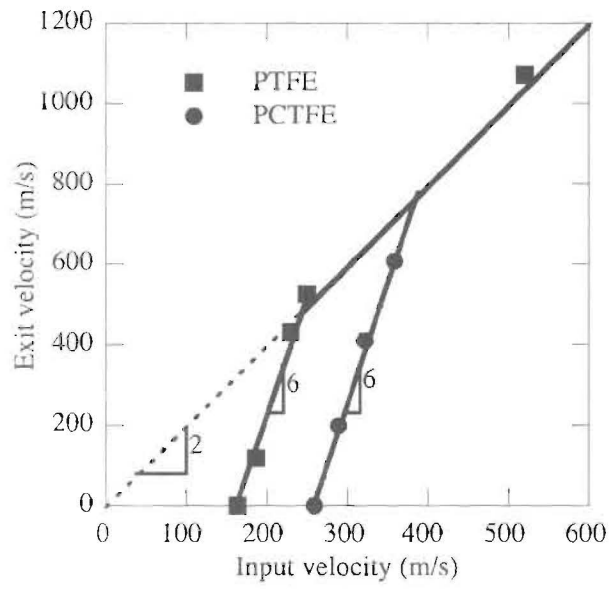

Figure 2. Dynamic-Tensile-Extrusion exit velocity for PTFE and PCTFE as a function of input velocity.

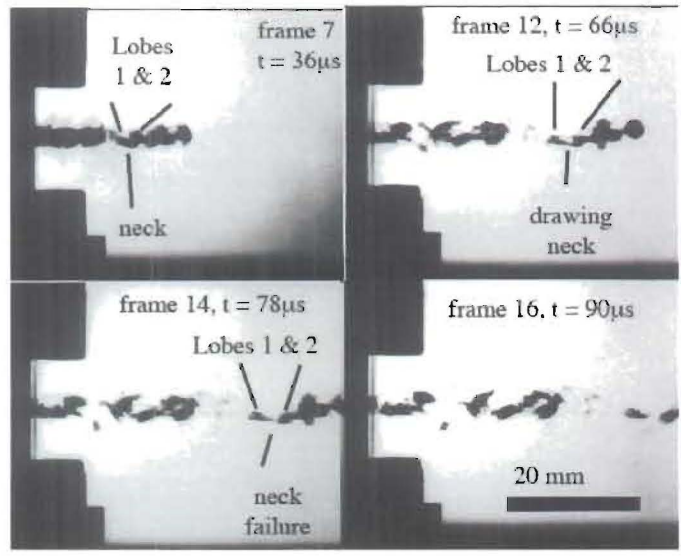

Figure 3. Select frames from a high-speed photographic sequence of dynamic tensile extrusion of PCTFE at $358 \mathrm{~m} \mathrm{~s}^{-1}$ highlighting in flight necking [21]. the highest tensile stress. As the velocity increased the number and size of penny shaped cracks increased, propagated to the surface of the sample. However, even above the transition the pieces fractured from the Taylor rod remained relatively small in number and large in size. As only the particles that separate and flow from the primary Dyn-Ten-Ext sample in the die are observed, the threshold for extrusion through the die of the DynTen-Ext is likely to be more equivalent to the upper velocity end of the ductile-to-brittle transition of the Taylor Impact. That said, the velocity threshold for extrusion through the die of the Dyn-Ten-Ext is 58\% higher for PCTFE than PTFE. Therefore, the difference in velocity required for failure between PCTFE and PTFE is even more pronounced for the Dyn-Ten-Ext than for Taylor Impact. In other words, not only is PCTFE more resistant to failure than PTFE under both loading techniques, under the more tension-dominated Dyn-Ten-Ext PCTFE exhibits an even greater resistant to failure. However, once the threshold for particulation is achieved, both polymers exhibit an increase in exit velocity at six times the rate of the increase in input velocity. This appears to hold up to the point where exit velocity is twice the input velocity.

An example of the high-speed photographic sequence for PCTFE under Dyn-Ten-Ext loading is shown in Fig. 3. A more complete discussion of Dyn-Ten-Ext measurements on PTFE and PCTFE with associated complete photographic sequences have recently been reported by Brown et al. [21]. Previous studies employing Dyn-Ten-Ext on metals have been typified by elongation and a propensity for plastic instabilities leading to a relatively small number of stable lenticular segments $[17,20]$. Under post-mortem investigation the segments have been realigned to determine the total elongation and relate it to velocity. For both PTFE and PCTFE the particulation is far more extensive making any post mortem realigned impractical. Moreover, even over the course of the sequences shown, the lead particles can be observed to relax significantly. This issue has previously been discussed for post mortem investigation of polymer Taylor Impact specimens [22]. Over the range of velocities investigated, above the threshold PTFE particulated in a dense stream of fragments smaller than $1 \mathrm{~mm}$ and with no signs of elongation. On the other hand, PCTFE exhibited a smaller number of particles, which were observed to be greater than $1 \mathrm{~mm}$ in size and with an 
aspect ratio of two or larger. The aspect ratio suggests an extension or stable plasticity process prior to the onset of damage evolution. Even during the flight of the extruded particulates the PCTFE continues to draw in the necking regions to the point of failure, as pointed to in Fig. 3.

\section{CONCLUSIONS}

Dynamic-Tensile-Extrusion (Dyn-Ten-Ext) experiments have been utilized to probe the dynamic tensile responses of PTFE and PCTFE. These fluoropolymers exhibit more irregular deformation and stochastic-based damage and failure mechanisms than the stable plastic elongation and shear instabilities observed in metals. The technique elucidates a number of tensile mechanisms that are consistent with quasi-static, SHPB, and Taylor Impact results. Similar to the observed ductile-tobrittle transition for Taylor Impact loading, PCTFE. failure occurs at a peak velocity greater than for PTFE. However, for the Dyn-Ten-Ext PCTFE exhibits even greater resistance to failure due to the tensile stress-state. While PTFE generates a large number of small fragments when extruded through the die, PCTFE draws out a smaller number of larger particles that dynamically evolve during the extrusion process through a combination of local necking mechanisms and bulk relaxation. Under Dyn-Ten-Ext loading, the propensity of PTFE to fail along normal planes is observed without indication of any localization, while the PCTFE clearly forms necks during the initial extrusion process that continue to evolve. There is clearly greater opportunity to investigate the extruded samples post mortem towards understanding the active deformation mechanisms and the below threshold spheres for deformation and any onset of damage, these will be a focus of future work.

\section{ACKNOWLEDGMENTS}

Los Alamos National Laboratory is operated by LANS, LLC, for the NNSA of the US Department of Energy under contract DE-AC52-06NA25396. This research was supported under the auspices of the US Department of Energy and the Joint DoD/DOE Munitions Program.

\section{REFERENCES}

1. Brown E.N., Rae P.J., Gray G.T. III, J. de Physic. IV 134, 935, 2006.

2. Brown E.N. and Dattelbaum D.M., Polymer 46, 3056,2005

3. Rae P.J., Brown E.N., Clements B.E., and Dattelbaum D.M., J. Appl. Phys. 98, 063521, 2005.

4. Bourne N.K., Brown E.N., Millett J.C.F., Gray G.T. III, J. Appl. Phys. 103, 074902, 2008.

5. Brown E.N., Dattelbaum D.M., Brown D.W., Rae P.J., Clausen B., Polymer 48, 253I, 2007.

6. Rae P.J. and Brown E.N., Polymer 46, 8128, 2005.

7. Rae P.J. and Dattelbaum D.M., Polymer 45, 7615, 2004.

8. Jordan J.L., Siviour C.R., Foley J.R., Brown E.N., Polymer 48, 4184, 2007.

9. Brown E.N., Rae P.J., Dattelbaum D.M., Clausen B., Brown D.W., Experimental Mechanics 48, 119, 2008.

10. Brown E.N., Clausen B., Brown D.W., J. Neutron Res. 15, 139, 2007.

11. Boume N.K., Millett J.C.F., Brown E.N., Gray G.T. III, J. Appl. Phys. 102, 063510, 2007.

12. Brown E.N., Rac P.J., Liu C., Maters. Sci. Engng. A 468-470, 253.2007.

13. Brown E.N., Trujillo C.P., Gray G.T. III, Rae P.J., Bourne N.K., J. Appl. Phys. 101, 024916, 2007.

14. Brown E.N., Rae P.J., Orler E.B. Gray G.T. III, and Dattelbaum D.M., Mater. Sci. Engng. C 26, 1338 , 2006.

15. Bourne N.K., Gray G.T. III, J. Appl. Phys. 93, 8966, 2003.

16. Brown E.N., Rae P.J., Orler E.B., Polvmer 47, 7506, 2006.

17. Gray III G.T., Cerreta E., Yablinsky C.A., Addessio L.B., Henrie B.L., Sencer B.H., Burkett M., Maudlin P.J., Maloy S.A., Trujillo C.P., Lopez M.F., in Shock Compression of Condensed Matter, 2007 (M. Elbert, M.D. Fumish, R. Chau, N. Holmes, J. Nguyen, eds.) pp. 725-728.

18. Cao F., Cerreta E.K., Trujillo C.P., Gray G.T. III, Acta Materialia 56, 5804, 2008.

19. Taylor G.I., Proc. Roy. Soc. London A 194, 289, 1948.

20. Gray G.T. III, in ASM Metals Handbook Volume 8, "Mechanical Testing and Evaluation ", $2000(\mathrm{H}$. Kuhn and D. Medlin, eds) pp. $462-476$.

21. Brown E.N., Trujillo C.P., Gray G.T. III J. Physic. $I V$ France in press 2009.

22. Brown E.N., Trujillo C.P., Gray G.T. III, in Shock Compression of Condensed Matter, 2007 (M. Elbert, M.D. Furnish, R. Chau, N. Holmes, J. Nguyen, eds.) pp. 691-694. 